\title{
Detection of haemoglobin using an adsorption approach at a liquid - liquid microinterface array
}

\author{
Eva Alvarez de Eulate, Lauren Serls and Damien W. M. Arrigan * \\ Nanochemistry Research Institute, Department of Chemistry, Curtin University, GPO Box \\ U1987, Perth, WA 6845, Australia \\ * Email: d.arrigan@curtin.edu.au; fax: +61-8-9266-2300.
}

\begin{abstract}
The behaviour of haemoglobin $(\mathrm{Hb})$ at the interface between two immiscible electrolyte solutions (ITIES) has been examined for analytical purposes. When $\mathrm{Hb}$ is fully protonated under acidic conditions $(\mathrm{pH}<\mathrm{pI})$ in the aqueous phase, it undergoes a potential-dependent adsorption and complexation, at the interface, with the anions of the organic phase electrolyte. When utilised as a simple and fast preconcentration step, consisting of adsorbing the protein at the interface, in conjunction with voltammetric desorption. This opens up the ITIES to the adsorptive stripping voltammetry (AdSV) approach. Utilising a $60 \mathrm{~s}$ adsorption step and linear sweep voltammetry, a linear response to $\mathrm{Hb}$ concentration in aqueous solution over the range $0.01-0.5 \mu \mathrm{M}$ was achieved. The equation of the best-fit straight-line was $I_{p}=$ 7.46 $C-0.109, R=0.996$, where $I_{p}$ is the peak current (nA) and $\mathrm{C}$ is haemoglobin concentration $(\mu \mathrm{M})$. The calculated detection limit $(3 \sigma)$ was $48 \mathrm{nM}$ for a $60 \mathrm{~s}$ preconcentration period, while the relative standard deviation was $13.3 \%$ for 6 successive measurements at $0.1 \mu \mathrm{M} \mathrm{Hb}$. These results illustrate the prospects for simple, portable and rapid label-free detection of biomacromolecules offered by electrochemistry at arrays of liquid-liquid microinterfaces.
\end{abstract}


Keywords: Haemoglobin, adsorption, ITIES, liquid-liquid interface, adsorptive stripping voltammetry

\section{Introduction}

Haemoglobin is a metalloprotein from red blood cells responsible for oxygen transport in the blood of vertebrates. It possesses a quaternary structure comprised of four subunits, two $\alpha$ and two $\beta$ polypeptide chains, in a tetrahedral arrangement. Each of these subunits is associated with a haem group. ${ }^{1}$ The study of haemoglobin is especially relevant as it is an important biomolecule particularly in the fields of medicine, pharmacology and diagnostics. Studies on this molecule may also be transposed to other important molecules of biological significance such as glycated haemoglobin (HbA1c), myoglobin and cytochrome c. Simple and rapid determination of low concentrations of haemoglobin is desirable as the biomacromolecule may be present in samples, either as an analyte of interest that indicates an incidence of disease, or as a possible interferent in the measurement of other analytes. For instance, Shi et al. developed a non-invasive micro-sensor to diagnose gastrointestinal bleeding based on an electron transfer microelectromechanical system (MEMS) which achieved a detection limit of $0.1 \mathrm{mg} / \mathrm{mL}(1.6 \mu \mathrm{M})$ of $\mathrm{Hb}$ under physiological conditions. ${ }^{2}$

To-date, the detection of a wide range of haemoglobin molecules such as glycated (HbA1c), fetal (HbF), and $\mathrm{C}(\mathrm{HbC})$ haemoglobin has been performed mostly by colourimetric assays or immunoassays. For instance, several point-of-care testing (POCT) devices are commercially available for HbA1c detection in diabetes diagnosis. ${ }^{3}$ Colourimetric assays are constrained by the detection limits and the interference of other biomolecules, while immunoassays require expensive reagents, several pre-treatment steps and longer periods of time from the collection of the sample until final analytical results are available. 
However, over recent decades electrochemistry has shown its potential as a possible selective, sensitive, portable, disposable, inexpensive and relatively simple technology for biomedical applications. The best example is the commercially-available glucose sensor for monitoring of blood glucose levels in diabetic patients. This biosensor represents about $85 \%$ of the biosensor market. ${ }^{4}$ Additionally, determination of blood electrolytes using ion selective electrodes is another important group of sensors widely accepted and under continuous development for biomedical diagnosis purposes. ${ }^{5}$

Electrochemistry at the liquid-liquid interface (or at the interface between two immiscible electrolyte solutions, ITIES) has been developed over the last 40 years. ${ }^{6-7}$ Processes studied at the ITIES do not necessarily depend on electron transfer, but more generally charge transfer involving either ion transfer or electron transfer (or both) can be studied and manipulated for detection and determination purposes. The electrochemistry and electrochemical determination at the ITIES of a range of biomolecules such as dopamine, ${ }^{8}$ heparin, ${ }^{9}$ insulin, ${ }^{10}$ lysozyme, ${ }^{11}$ cytochrome c, ${ }^{12}$ myoglobin ${ }^{13}$ haemoglobin, ${ }^{14}$ small peptides ${ }^{15}$ and $\mathrm{DNA}^{16}$ has been explored by diverse groups worldwide. The latest studies have focused attention towards reaching lower limits of detection basing the detection on voltammetric techniques combined with pre-treatment steps. For example, Collins et al. reported the detection of propanolol in artificial saliva using differential pulse stripping voltammetry. ${ }^{17-18}$ Recent work performed by our group has already shown the potential of adsorptive stripping voltammetry $(\mathrm{AdSV})$ as an important tool for achieving lower limits of detection at the microITIES. ${ }^{19}$

The aim of the present work was to investigate whether the adsorptive stripping voltammetry approach at the microITIES was generically applicable to biomacromoelcules, with haemoglobin chosen as a protein that has been studied at the ITIES previously, but not 
subjected to adsorptive accumulation, and that is also of interest as a possible biomarker for disease. The present work provides the basis for a new reagentless, simple, fast and competitive technique with the capability to be miniaturised and integrated other analytical technologies.

\section{Material and methods}

\section{Reagents}

All reagents were purchased from Sigma-Aldrich Australia Ltd, and used as received. The electrolyte salt of the organic phase, bis (triphenylphosphoranylidene) ammonium tetrakis (4chlorophenylborate) $\left(\mathrm{BTPPA}^{+} \mathrm{TPBCl}^{-}\right)$was prepared by metathesis of bis (triphenylphosphoranlidene) ammonium chloride $\left(\mathrm{BTPPA}^{+} \mathrm{Cl}^{-}\right)$and potassium tetrakis (4chlorophenyl) borate $\left(\mathrm{K}^{+} \mathrm{TPBCl}^{-}\right)$. The organic phase consisted of $10 \mathrm{mM} \mathrm{BTPPA}{ }^{+} \mathrm{TPBCl}^{-}$in 1,6-dichlorohexane, which was gelled using low molecular weight poly(vinyl chloride). ${ }^{20-21}$ Aqueous stock solutions of haemoglobin (from bovine blood) were prepared in $10 \mathrm{mM} \mathrm{HCl}$ on a daily basis. All aqueous solutions were prepared in purified water from a USF Purelab Plus UV (resistivity: $18 \mathrm{M} \Omega \mathrm{cm}$ ).

\section{Apparatus}

All measurements were performed using an Autolab PGSTAT302N analyser (Metrohm, The Netherlands). The micropore membranes, used to form an array of microITIES, were fabricated using photolithographic patterning and a combination of wet and dry silicon etching. Deep reactive ion etching was used for pore drilling and produces hydrophobic fluorocarbon-coated internal pore walls which subsequently are filled with the organic phase. The array employed here consisted of 30 micropores in a hexagonal close-packed arrangement, each with a diameter of $22.4 \mu \mathrm{m}$ and a pore centre-to-centre distance of 200 
$\mu \mathrm{m} .{ }^{22-23}$ The microporous silicon membranes were sealed onto a glass cylinder using silicone rubber (acetic acid curing Selleys glass silicone, Selleys Australia \& New Zealand). Then the gelled organic phase solution was introduced into the silicon micropore arrays, and the organic reference solution was placed on top of the gelled organic phase. ${ }^{15}$ The gel/membrane/glass assembly was then inserted into the aqueous phase $(10 \mathrm{mM} \mathrm{HCl}$ or haemoglobin in $10 \mathrm{mM} \mathrm{HCl}$ ) and voltammetric experiments implemented. Transfer of tetraethylammonium $\left(\mathrm{TEA}^{+}\right)$across the interface was performed to characterize the array and confirm the correct filling of the pores. $\mathrm{TEA}^{+}$transfer at the microITIES (data not shown) exhibited steady-state voltammetry on the forward scan (ion transfer from aqueous to organic phase) and peak-shaped voltammetry on the reverse scan (organic to aqueous phase), consistent with pores filled with organic phase, as previously reported. ${ }^{22-23}$

\section{Electrochemical cell}

A two-electrode electrochemical cell was employed, whereby, the micro-interface array was polarised by applying a potential difference between two $\mathrm{Ag} / \mathrm{AgCl}$ electrodes (one in each phase). Scheme 1 represents the electrochemical cell used, where $x$ is the concentration of haemoglobin in the aqueous phase.

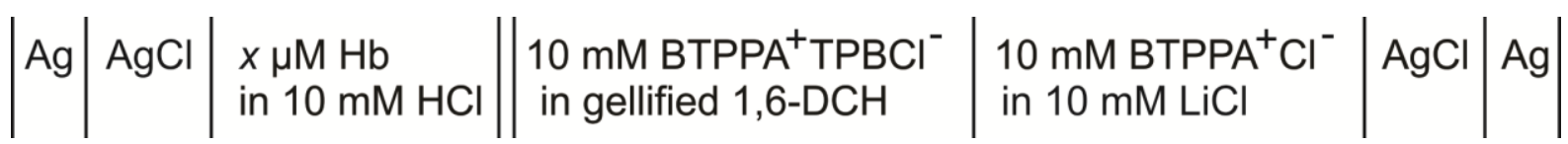

Scheme 1. Schematic representation of the electrochemical cell.

Cyclic voltammetry (CV) and adsorptive stripping voltammetry (AdSV) were carried out at a sweep rate of $5 \mathrm{mV} \mathrm{s}^{-1}$. Parameters such as protein concentration, applied potential, and duration of the adsorption stage were varied. 


\section{Results and discussion}

The experiments presented below have been performed at $\mathrm{pH} \mathrm{2,} \mathrm{which} \mathrm{is} \mathrm{below} \mathrm{the}$ isoelectric point $(p I=6.8)^{1}$ of haemoglobin and where it is assumed to be fully protonated with a charge $z_{i}$ of $+62 .{ }^{14}$ It is reported that at $\mathrm{pH}<2.5$, haemoglobin retains a large amount of tertiary structure and is only partially denatured. ${ }^{24}$ Under these conditions, this protein has shown electroactivity at liquid-liquid interfaces and can be detected via the facilitated anion transfer mechanism at the micro-interface array, in agreement with previous reports. ${ }^{14} \mathrm{CV}$ analysis (Figure 1) confirmed this proposed mechanism at the gelled microITIES array, involving adsorption of the positively-charged haemoglobin on the interface at the more positive potentials in conjunction with facilitated transfer of organic phase anions. The sharp peak observed on the reverse sweep at ca. $0.65 \mathrm{~V}$ is characteristic of a desorption process, whereas on the forward sweep, an increase in current, relative to the background, and the presence of a pair of shoulders are indicative of charge transfer occurring. However the latter processes (shoulders) are insufficiently defined to be used for analytical purposes. Thus, $\mathrm{Hb}$ is electroactive at the microITIES array, but implementation of an advanced voltammetric strategy may offer better detection capability and that is the focus of this paper. 


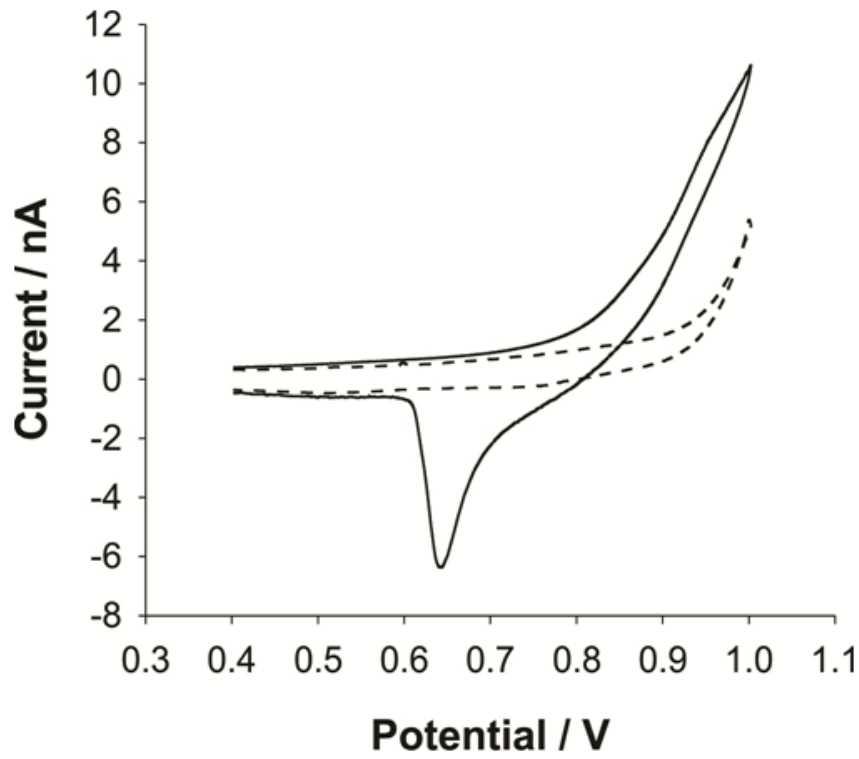

Figure 1. Cyclic voltammetry of $10 \mu \mathrm{M} \mathrm{Hb}$ (solid line) at the microITIES array. Sweep rate: $5 \mathrm{mV} \mathrm{s}^{-1}$. The dashed line is the response in the absence of haemoglobin. The full cell description is given in Scheme 1.

\section{Potential dependence}

AdSV is an electroanalytical technique that involves two steps: first, preconcentration of the analyte by adsorption at the electrified interface, and second, the voltammetric desorption of the analyte from the interface. This methodology has been proven to enhance the detection capability in electrochemical analysis ${ }^{25}$ and specifically at the micro-ITIES when employing lysozyme, ${ }^{19}$ a model globular protein. Previous reports on haemoglobin behaviour at the ITIES have suggested that the protein undergoes a complex process consisting of adsorption and facilitated anion transfer of the organic electrolyte. ${ }^{14,}{ }^{26}$ In order to optimise the conditions where haemoglobin is maximally adsorbed, a series of applied potentials across a range from 0.45 to $1.1 \mathrm{~V}$ was investigated (see Figure 2). When the applied potential was greater than that required for the protein to adsorb, haemoglobin facilitated an ion transfer involving charged protein and organic anion interactions. This is followed by desorption of the biomacromolecule from the interface and back transfer of the organic electrolyte anion to 
the organic phase during the subsequent voltammetric scan. As can be seen from Figure 1, $\mathrm{Hb}$ adsorption starts at $0.8 \mathrm{~V}$, reaching the maximum current peak height at $0.975 \mathrm{~V}$ with peak current of $-15 \mathrm{nA}$. When increasing the potential beyond this optimum value, organic electrolyte transfer across the interface without complexation of the protein dominates this process. Additional peak analysis (not shown here) confirms an optimum potential applied of $0.975 \mathrm{~V}$ when the ratio between the half-width and the peak height of the reverse peak was also analysed. Moreover, this optimum potential differs to that obtained for lysozyme $(0.950$ V) ${ }^{19}$ under the same conditions, indicating some favourable selectivity of the system in the electrochemical adsorption. Furthermore, the voltammetric peak during the desorption process was also different, $0.65 \mathrm{~V}$ for $\mathrm{Hb}$ and $0.7 \mathrm{~V}$ for lysozyme. Nevertheless, the possible interference of other proteins, such as serum albumin present in blood samples, must be addressed in order to determine the capability of this method within a more complex sample matrix.

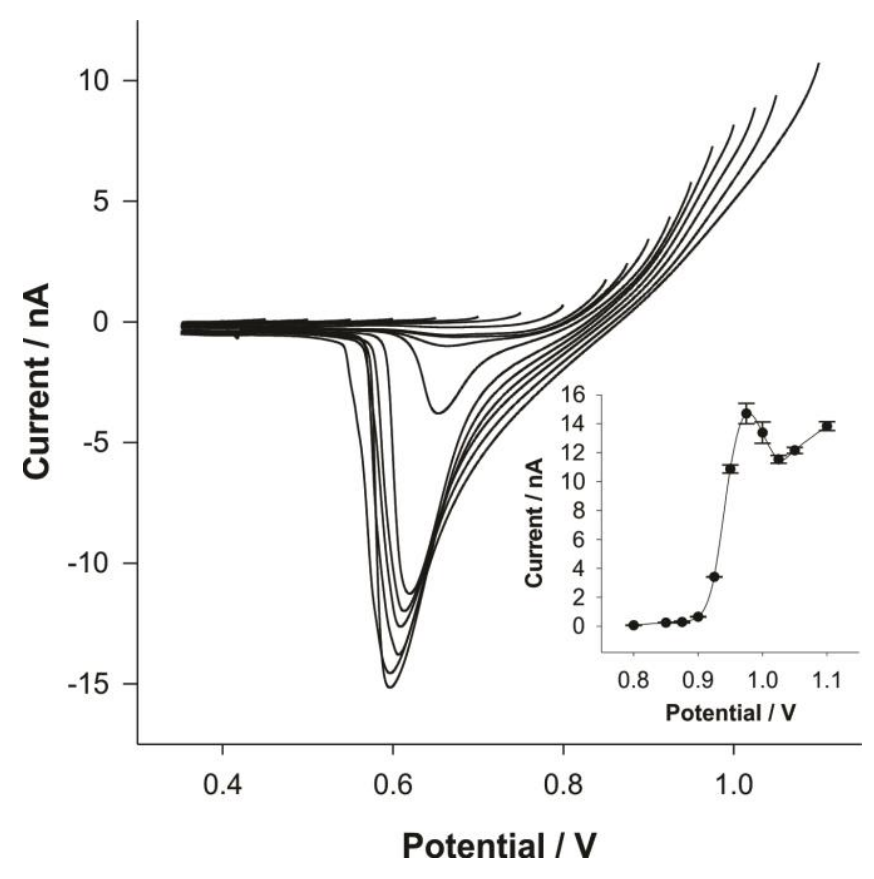

Figure 2. AdSV of $5 \mu \mathrm{M} \mathrm{Hb}$ at the microITIES array following application of different applied potentials (between 0.45 and $1.10 \mathrm{~V}$ ) for the adsorption step of $60 \mathrm{~s}$. Inset: evolution 
of the peak current with the applied potential of the adsorption step. Electrochemical cell composition as indicated in Scheme 1. Error bars represent \pm 1 standard deviation $(n=3)$.

\section{Preconcentration time dependence}

The influence of the preconcentration time at a fixed haemoglobin concentration also investigated. Figure 3 shows the evolution of the desorptive voltammograms with preconcentration time following adsorption of the protein at $0.975 \mathrm{~V}$ for different periods of time, from 0 to $1800 \mathrm{~s}$. The inset in Figure 3 shows a hyperbolic increase of the desorption peak current when the preconcentration time is increased. However, adequate sensitivity to $\mathrm{Hb}$ is obtained at short preconcentration times. Furthermore, it can be seen that the peak shape becomes skewed at the longer times, indicating a possible loss of sensitivity or resolution.

Thus both the applied potential and time for adsorption have an impact on the detection signal and were fully characterized before studying the performance potential of the approach under different concentrations of the protein in the aqueous phase. The electrochemical response suggests that the adsorption of haemoglobin at the $\mu$ ITIES can be controlled by the solution concentration and the preconcentration time. 


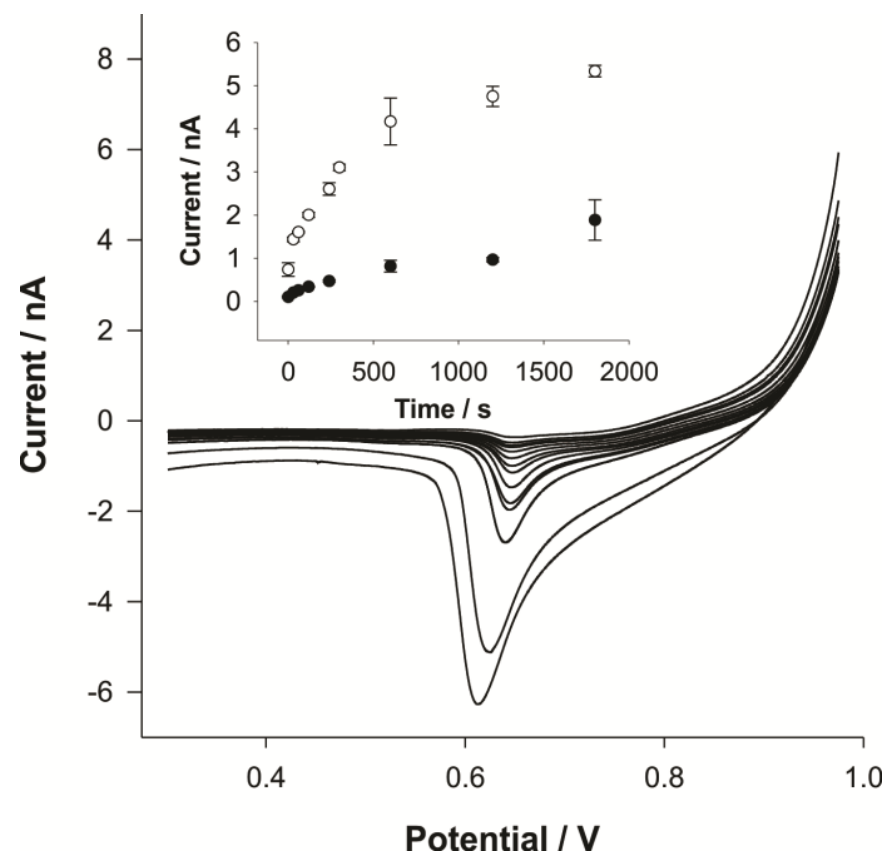

Figure 3. AdSV of $1 \mu \mathrm{M} \mathrm{Hb}$ at different preconcentration times, from 0 to $1800 \mathrm{~s}$. Inset: plot of peak current versus preconcentration time for (०) $1 \mu \mathrm{M}$ and $(\bullet) 0.1 \mu \mathrm{M} \mathrm{Hb}$. Electrochemical cell composition as given in Scheme 1. Error bars represent \pm 1 standard deviation $(\mathrm{n}=3)$.

\section{Concentration range for Haemoglobin detection}

AdSV of haemoglobin was performed using fixed adsorption times $(0,60,120$ and $300 \mathrm{~s})$ across an extensive concentration range $(0.005-7.5 \mu \mathrm{M})$. Figure 4 shows the resultant voltammograms for (A) $0 \mathrm{~s}$ and (B) $60 \mathrm{~s}$ preconcentration times. The minimum measurable desorptive (stripping) peak corresponds to a concentration in the aqueous phase of $30 \mathrm{nM}$, for a preconcentration time of $60 \mathrm{~s}$, whilst without pre-treatment (i.e. $0 \mathrm{~s}$ preconcentration) this value increased up to $70 \mathrm{nM}$, in line with previous studies by $\mathrm{CV}$. A common feature was noticed in all of the voltammograms at $2 \mu \mathrm{M} \mathrm{Hb}$ in the bulk aqueous phase (see Figure 4). At that critical concentration, a crossover at $0.8 \mathrm{~V}$ is observed and the peak current regresses significantly. This process breaks the linearity observed at lower protein concentration in the aqueous solution. As noted in previous work, ${ }^{19}$ multilayer formation has been demonstrated 
to occur at the liquid-liquid interfaces when protein is concentrated at the interface. Consequently, protein conformational changes are possible within the multilayers that built up at the microITIES, and perhaps there is less interaction between haemoglobin and the organic phase anion at higher concentrations due to the difference between interfacial and bulk concentration. Further studies on this observation are required for a fuller explanation.

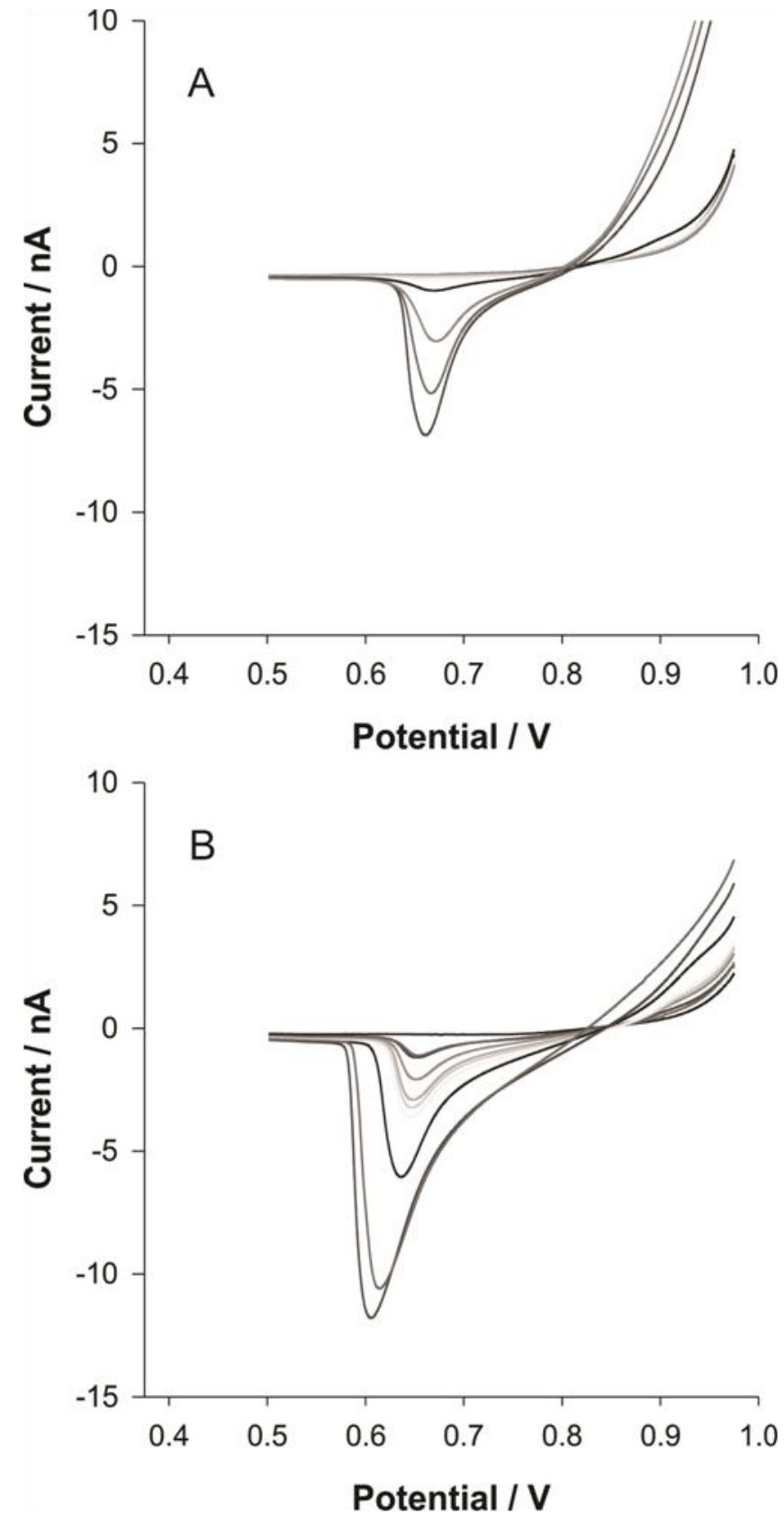


Figure 4. AdSV of different concentrations of $\mathrm{Hb}, 0.01,0.05,0.1,0.25,0.5,1,1.5,2.5,5$ and $7 \mu \mathrm{M}$. (A) with $0 \mathrm{~s}$ preconcentration step and (B) after $60 \mathrm{~s}$ preconcentration.

The build-up of multilayers was characterised by determining the interfacial coverage of the adsorbed protein at the microITIES. Interfacial coverage $(\Gamma)$ values were estimated using equation (1) where $Q$ is the charge under the desorption peaks, assuming the charge of the protein $z_{i}$ is +62 when fully protonated at $\mathrm{pH} 2, F$ is the Faraday constant and $A$ is the geometric area of the microinterface array $\left(1.18 \cdot 10^{-4} \mathrm{~cm}^{2}\right)$.

$$
Q=z_{i} F A \Gamma
$$

Taking into account that a molecule of haemoglobin occupies a cross-sectional area of 30 $\mathrm{nm}^{2}$ and that for the formation of a single monolayer, only $87 \%$ of the interface is occupied by haemoglobin in a close-packed hexagon configuration, then $3.4 \cdot 10^{8}$ molecules would be absorbed and occupying the available geometric area of the micro-interface array $\left(1.18 \cdot 10^{-4}\right.$ $\mathrm{cm}^{2}$ ). Without preconcentration conditions, the experimental interfacial coverage values for $\mathrm{Hb}$ bulk concentrations lower than $2.5 \mu \mathrm{M}$ correspond to less than a monolayer, while the formation of multilayers occurs at higher concentrations (between 8 to 19 monolayers in the concentration range 5-10 $\mu \mathrm{M}$, without preconcentration).

Subsequently linearity was investigated at low concentration of haemoglobin in the bulk aqueous solution. Table 1 summarises the analytical behaviour of this method over the range from 5 to $500 \mathrm{nM} \mathrm{Hb}$ using four different preconcentration times $(0,60,120$ and $300 \mathrm{~s})$. At 0 s preconcentration time, the calculated limit of detection (LOD) was $0.265 \mu \mathrm{M}$, while amongst the results obtained from the longer preconcentration times, $60 \mathrm{~s}$ preconcentration gave best performance in terms of LOD, linearity, minimum observable peak and enhanced peak current (at $0.5 \mu \mathrm{M})$. The calibration curve obtained after the $60 \mathrm{~s}$ preconcentration step 
was: $I_{p}(n A)=7.46\left(n A \mu M^{-1}\right) \cdot C(\mu M)-0.109(n A), R=0.996$, where $I_{p}$ is current of the desorptive voltammetry peak and $C$ is the concentration of the protein in bulk aqueous solution (see Figure 5). The relative standard deviation was $13.3 \%$ for 6 successive measurements at $0.1 \mu \mathrm{M}$ of haemoglobin following $60 \mathrm{~s}$ preconcentration. This experiment showed that haemoglobin was completely stripped away from the interface, with intermediary blank scans displaying no peaks. The lowest observable and measurable desorption peak corresponded to $30 \mathrm{nM}$ while the calculated limit of detection (LOD) was 48 $\mathrm{nM}$ for a preconcentration period of $60 \mathrm{~s}$. This calculated LOD is based on three times the standard deviation of the intercept and the value larger than the experimentally detectable concentration reflects the precision of the measurements. Previous work based on cyclic voltammetry reported by Herzog et al. presented a non-linear behaviour ${ }^{14}$ of $\mathrm{Hb}$ at a millimetre-sized ITIES (not gelled as in the present work) whilst the detection of $0.55 \mu \mathrm{M} \mathrm{Hb}$ was achieved after haemoglobin digestion and the use of differential pulse stripping voltammetry as a more sensitive voltammetric technique. ${ }^{27}$ However, the LOD under similar conditions to those presented here (AdSV for $60 \mathrm{~s}$ ) was $60 \mathrm{nM}$ of lysozyme. ${ }^{19}$ Based on these results, AdSV at arrays of liquid-liquid microinterfaces is a viable analytical approach for simple, fast and label-free detection of haemoglobin.

Table 1. Analytical characteristics of $\mathrm{Hb}$ at different pre-concentration times.

\begin{tabular}{|c|c|c|c|c|c|c|c|c|}
\hline $\begin{array}{c}\text { Pre- } \\
\text { concentration } \\
\text { times /s }\end{array}$ & $\begin{array}{c}{[\mathrm{Hb}]_{\min }} \\
\text { observa } \\
\text { ble / } \\
n M\end{array}$ & $\begin{array}{c}\text { Peak } \\
\text { current } \\
\text { of } \\
{[H b]_{\text {min }}} \\
/ n A\end{array}$ & $\begin{array}{c}\text { Peak } \\
\text { current at } \\
0.5 \mu M H b \\
/ n A\end{array}$ & $\begin{array}{c}\text { Calibrati } \\
\text { on graph } \\
\text { slope / } \\
\text { nA } \mu M^{-1}\end{array}$ & $\begin{array}{c}\text { Linear } \\
\text { range / } \\
\mu M\end{array}$ & $\begin{array}{c}\text { Numbe } \\
\text { r of } \\
\text { points } \\
(N)\end{array}$ & $\begin{array}{c}\text { Limit of } \\
\text { detection } \\
(\text { LOD }) / \\
n M\end{array}$ & $\begin{array}{c}\text { Correlati } \\
\text { on } \\
\text { coefficien } \\
t(r)\end{array}$ \\
\hline 0 & 70 & 0.04 & 0.63 & 1.32 & $\begin{array}{c}0.07 \text { - } \\
0.5\end{array}$ & 8 & 265 & 0.997 \\
\hline 60 & 30 & 0.04 & 3.41 & 7.46 & $\begin{array}{c}0.03- \\
0.5\end{array}$ & 12 & 48 & 0.996 \\
\hline 120 & 30 & 0.05 & 4.47 & 9.07 & $\begin{array}{c}0.03- \\
0.5\end{array}$ & 12 & 68 & 0.991 \\
\hline 300 & 30 & 0.08 & 6.72 & 13.5 & $\begin{array}{c}0.03- \\
0.5\end{array}$ & 12 & 89 & 0.984 \\
\hline
\end{tabular}




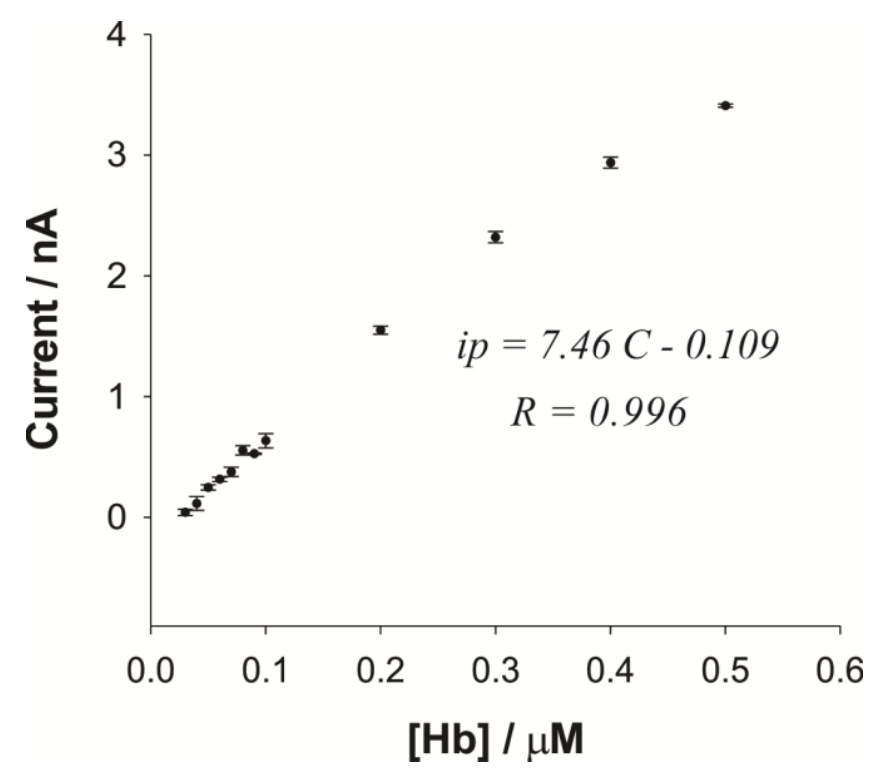

Figure 5. Current versus concentration curve of haemoglobin $(0.01-0.5 \mu \mathrm{M})$ for $60 \mathrm{~s}$ preconcentration time. Error bars represent \pm 1 standard deviation $(\mathrm{n}=3)$.

\section{Conclusions}

An analytical approach based on constant-potential adsorption of protein followed by voltammetric desorption enables the detection of lower levels of haemoglobin in aqueous solution. A calculated detection limit of $48 \mathrm{nM}$ was achieved following $60 \mathrm{~s}$ adsorption at the aqueous-organogel micro-interface array. Previous studies have highlighted that protein detection at the ITIES may be attributed to a combination of adsorption and proteinfacilitated transfer of organic phase electrolyte anions. The results of this study show that this adsorption event may be exploited for analytical purposes, in this case within a thirty-member array of micro-interfaces. The improvement in detection limit is two orders of magnitude better than has been achieved by cyclic voltammetry at macro liquid-liquid interfaces ${ }^{27}$ and the same order of magnitude as obtained when applying the strategy to lysozyme detection. ${ }^{19}$ A lower measurable peak was obtained when analysing haemoglobin than lysozyme, which can be attributed to haemoglobin's higher positive charge ( +17 in the case of lysozyme, +62 
for haemoglobin). A higher degree of charge of the biomacromolecule enables a higher interaction with the anions from the organic phase, increasing the sensitivity of the system. The interference of other proteins in matrices such as blood must be addressed. Nevertheless, this report presents the fundamentals for a new area based on the capability of this technology which may be extrapolated to an extensive range of molecules.

\section{Acknowledgements}

This work was supported by Curtin University and the Western Australian Nanochemistry Research Institute. EAdE is a recipient of a Curtin Strategic International Research Scholarship. The micromachined silicon membranes were a gift from Tyndall National Institute, Cork, Ireland. We thank Sharon Fletcher for carrying out some experiments.

\section{References}

1. Garrett RH, Grisham CM, Biochemistry (2010) 4th Edition ed., Brooks / Cole, Boston

2. Shi J, Yan GZ, Wang KD, Fang Y, Non-invasive method to detect and locate haemorrhagic focus of GI tract, J Med Eng Technol (2007) 31:123-128

3. Warsinke A, Point-of-care testing of proteins, Anal Bioanal Chem (2009) 393:13931405

4. Wang J, Electrochemical glucose biosensors, Chem Rev (2008) 108:814-825

5. Dimeski G, Badrick T, St John A, Ion Selective Electrodes (ISEs) and interferences-A review, Clin Chim Acta (2010) 411:309-317

6. Samec Z, Electrochemistry at the interface between two immiscible electrolyte solutions, Pure Appl Chem (2004) 76:2147-2180

7. Arrigan DWM, Bioanalytical Detection Based on Electrochemistry at Interfaces between Immiscible Liquids, Anal Lett (2008) 41:3233-3252

8. Ribeiro JA, Miranda IM, Silva F, Pereira CM, Electrochemical study of dopamine and noradrenaline at the water/1,6-dichlorohexane interface, Phys Chem Chem Phys (2010) 12:15190-15194

9. Amemiya S, Kim Y, Ishimatsu R, Kabagambe B, Electrochemical heparin sensing at liquid/liquid interfaces and polymeric membranes, Anal Bioanal Chem (2011) 399:571-579

10. Kivlehan F, Lanyon YH, Arrigan DWM, Electrochemical study of insulin at the polarized liquid-liquid interface, Langmuir (2008) 24:9876-9882

11. Scanlon MD, Jennings E, Arrigan DWM, Electrochemical behaviour of hen-eggwhite lysozyme at the polarised water/1,2-dichloroethane interface, Phys Chem Chem Phys (2009) 11:2272-2280 
12. Osakai T, Yuguchi Y, Gohara E, Katano H, Direct Label-free Electrochemical Detection of Proteins Using the Polarized Oil/Water Interface, Langmuir (2010) 26:11530-11537

13. O'Sullivan S, Arrigan DWM, Electrochemical behaviour of myoglobin at an array of microscopic liquid-liquid interfaces, Electrochim Acta (2012) 77:71-76

14. Herzog G, Kam V, Arrigan DWM, Electrochemical behaviour of haemoglobin at the liquid/liquid interface, Electrochim Acta (2008) 53:7204-7209

15. Scanlon MD, Herzog G, Arrigan DWM, Electrochemical detection of oligopeptides at silicon-fabricated micro-liquid-liquid interfaces, Anal Chem (2008) 80:5743-5749

16. Kivlehan F, Lefoix M, Moynihan HA, Thompson D, Ogurtsov VI, Herzog G, Arrigan DWM, Interaction of acridine-calix[4]arene with DNA at the electrified liquid liquid interface, Electrochim Acta (2010) 55:3348-3354

17. Collins CJ, Arrigan DWM, Ion-Transfer Voltammetric Determination of the BetaBlocker Propranolol in a Physiological Matrix at Silicon Membrane-Based Liquid vertical bar Liquid Microinterface Arrays, Anal Chem (2009) 81:2344-2349

18. Collins CJ, Lyons C, Strutwolf J, Arrigan DWM, Serum-protein effects on the detection of the beta-blocker propranolol by ion-transfer voltammetry at a microITIES array, Talanta (2010) 80:1993-1998

19. Alvarez de Eulate E, Arrigan DWM, Adsorptive Stripping Voltammetry of Hen-EggWhite-Lysozyme via Adsorption-Desorption at an Array of Liquid-Liquid Microinterfaces, Anal Chem (2012) 84:2505-2511

20. Scanlon MD, Strutwolf J, Arrigan DWM, Voltammetric behaviour of biological macromolecules at arrays of aqueous-organogel micro-interfaces, Phys Chem Chem Phys (2010) 12:10040-10047

21. Osakai T, Kakutani T, Senda M, Ion-Transfer Voltammetry and Amperometric Chemical Sensors, J Electrochem Soc (1987) 134:C520-C520

22. Zazpe R, Hibert C, O'Brien J, Lanyon YH, Arrigan DWM, Ion-transfer voltammetry at silicon membrane-based arrays of micro-liquid-liquid interfaces, Lab Chip (2007) 7:1732-1737

23. Strutwolf J, Scanlon MD, Arrigan DWM, Electrochemical ion transfer across liquid/liquid interfaces confined within solid-state micropore arrays - simulations and experiments, Analyst (2009) 134:148-158

24. Kristinsson HG, Acid-induced unfolding of flounder hemoglobin: Evidence for a molten globular state with enhanced pro-oxidative activity, J Agric Food Chem (2002) 50:7669-7676

25. Kalvoda R, Review of Adsorptive Stripping Voltammetry - Assessment and Prospects, Fresen J Anal Chem (1994) 349:565-570

26. Herzog G, Moujahid W, Strutwolf J, Arrigan DWM, Interactions of proteins with small ionised molecules: electrochemical adsorption and facilitated ion transfer voltammetry of haemoglobin at the liquid-liquid interface, Analyst (2009) 134:16081613

27. Herzog G, Roger A, Sheehan D, Arrigan DWM, Ion-Transfer Voltammetric Behavior of Protein Digests at Liquid-Liquid Interfaces, Anal Chem (2010) 82:258-264 